\title{
NEW CONCEPTS AND TRENDS OF MCDM FOR TOMORROW - IN HONOR OF PROFESSOR GWO-HSHIUNG TZENG ON THE OCCASION OF HIS 70 ${ }^{\text {th }}$ BIRTHDAY
}

\author{
James J. H. LIOU \\ Department of Industrial Engineering and Management, National Taipei University of Technology, \\ No. 1, Section 3, Chung-Hsiao East Road, Taipei, Taiwan
}

\begin{abstract}
This article introduces several new concepts and trends in multiple criteria decision making (MCDM) for solving actual problems, as proposed by Professor Gwo-Hshiung Tzeng. These new concepts are as follows: (1) interdependency in real-world problems; (2) replacing the relative good solution from the existing alternatives using aspiration levels; (3) shifting from ranking and selection to performance improvement; (4) information fusion/aggregation; and (5) changeable decision spaces. To honor Prof. Tzeng's contribution in the MCDM field and to commemorate his $70^{\text {th }}$ birthday, this article also highlights his research career in MCDM and some publication list in the past 10 years.
\end{abstract}

Keywords: MCDM, MADM, MODM, DEMATEL, DANP, VIKOR, Changeable space, Aspiration level.

Reference to this paper should be made as follows: Liou, J. J. H. 2013. New concepts and trends of MCDM for tomorrow - in honor of Professor Gwo-Hshiung Tzeng on the occasion of his $70^{\text {th }}$ birthday, Technological and Economic Development of Economy 19(2): 367-375.

\section{New trends and concepts in MCDM}

Over the past two decades, the development of information technology (IT) has been characterized by a series of positive, but temporary, shocks. The alternate perspective is that IT in Internet communication has produced a fundamental change in the world, leading to a permanent improvement in fast growth-change prospects such as telephone, telegraph, Internet, smart phone, i-phone, i-pad, cloud computing, business, economy, society, and government. What are the prospects for future trends? Which problems will be solved regarding user/ customer/societal needs in marketing situations, and how can overall problems in dimensions and criteria be resolved using aspiration levels? The traditional MCDM field ignored some important new concepts and trends and needed several assumptions to solve real-world problems. Therefore, Prof. Tzeng proposed some new concepts for facing tomorrow's world. 
First, the traditional model assumes that the criteria in value-creation are independent and hierarchical in structure; however, criteria are often interdependent in real-world problems because 'Some statistics and economics assumptions are unrealistic in the real world'. The Decision Making Trial and Evaluation Laboratory (DEMATEL) technique is an effective tool to find the interrelationship matrix and building an influential network relation map (INRM) for solving relationship problems in the real world. Second, the relatively good solution from existing alternatives is replaced by aspiration levels to avoid "Choosing the best among inferior options/alternatives", i.e. "Picking the best apple among a barrel of rotten apples". Third, the emphasis in the field has shifted from ranking and selection when determining the most preferable approaches to performance improvement of existing methods based on INRM because "we need a systematic approach to problem-solving; instead of addressing the systems of the problem, we need to identify the sources of the problem". Fourth, Kahneman and Tversky (Kahneman received the Nobel Prize in Economics in 2002) developed the basic concept of the non-additive (or super-additive) value-function aggregation in multi-criteria problems in 1973. Simon incorporated the basic concept of the "aspiration level" in his work, receiving the Nobel Prize in Economics in 1978. The question that arises is "How can we implement these two concepts (non-additive value function and aspiration level) within real-world inter-relationship (dependence and feedback) problems?” Information fusion or aggregation/integration such as fuzzy integrals (basically, a non-additive or super-additive model) has been developed to aggregate/integrate performances. Therefore, to overcome the defects of the conventional Multiple Attributes Decision Making (MADM) method, a new Hybrid Dynamic Multiple Criteria Decision Making (HDMADM) method has been developed for solving complicated and dynamic problems in the real world and application to improve real issues, e.g. Internet communication, government overall policy improvement, etc. Fifth, classical Multiple Objectives Decision Making (MODM) methods are used to pursue an optimal solution in a fixed feasible region (objective space) based on fixed conditions or resources (decision space). A new thinking of MODM models with changeable spaces can help decision-makers reach a win-win for planning/designing and achieve the desired point (aspiration level), which is better than pursuing the ideal point or Pareto optimal solution.

\section{Profile of Professor Gwo-Hshiung Tzeng}

Prof. Gwo-Hshiung Tzeng was born in 1943 in Taiwan as the third child of a poor farmer. While still in his mother's womb, his father worked at the Mitsui Mining Company as the Director of the Manila (Philippine) Branch during World War II. His father (with all his employees) was drafted into the Japanese army to join the war, but never came back. As such, Prof. Gwo-Hshiung Tzeng never saw his father. He was raised by his mother and his grandparents in the difficult period of a ruined Taiwan after World War II.

In 1967, he received a Bachelor's degree in business management from the Tatung Institute of Technology (now Tatung University), Taiwan. In 1971, he received a Master's degree in urban planning from National Chung Hsing University (now National Taipei University), Taiwan. During his studies in Taiwan, he was enlightened by many excellent professors, such as Professor Lai-Chyan Yu (Chairman of the Department of Business Management, Economics), 


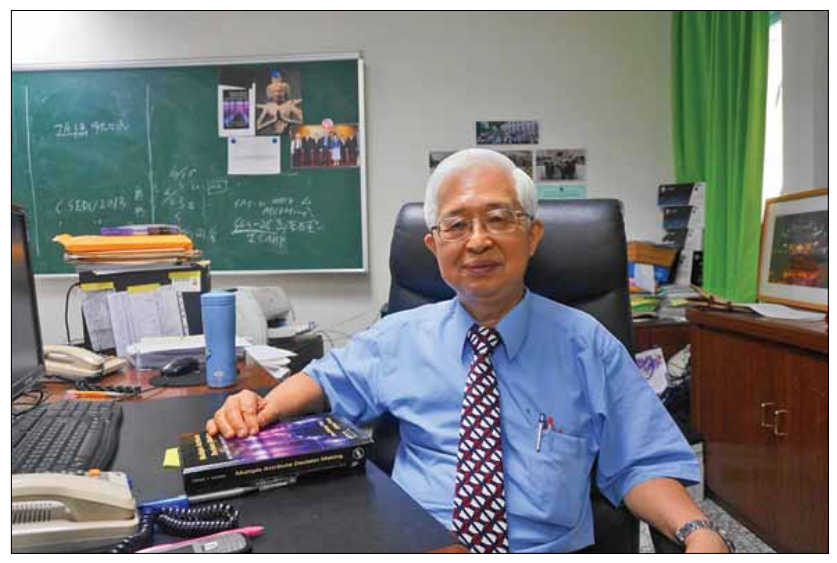

Professors Cheng-Chen Chen (Econometrics and Statistics) and Fu-Cheng Liu (Logic and Reasoning) from Taiwan University, and Professor Deng-Yuan Huang (Mathematic Analysis) from Academia Sinica, the preeminent academic institution in Taiwan. Through their guidance, Prof. Gwo-Hshiung Tzeng built a strong foundation in economics, mathematics, and statistics. He then worked in the Department of Transportation and Communication in Taiwan after receiving his Master's degree. From 1971 to 1973, he helped to build the first freeway during the economic recovery of Taiwan and also published his first book Introduction to Modern Statistics. As a result of his brilliant performance, he received financial support through research projects at Osaka University of Japan for further study in 1973.

In his Japanese study, he served under the direction of Prof. Yutaka Suzuki from Osaka University and Prof. Tamotsu Yokoyama from Tokyo University. Because of Prof. Suzuki's electrical system engineering background (40 years ago a member of the Club of Rome's report Limits to World Growth for World Dynamic Systems) and Prof. Tamotsu Yokoyama, whose majors were statistics, mathematics, operations research, and decision science (Prof. Yokoyama built the society of Operations Research of Japan about 60 year ago), Tzeng learned the importance of integrated sciences. During this period, in the first energy crisis of 1973, he joined or performed many interdisciplinary research projects, such as: "Regional Administrative Organization Decision-Process by PATTERN Method for Application Research" (Kansai Institute of Information System Research Report, March 1975); "Enterprise and Environment: The Location of Business from the View-Point of National, Social, Institutional-Environment" (Kansai Institute of Information System Research, March 1976); and "Survey Research on the Local Administration for Administrative Needs of Regional Residents (Science Research Institute, March 1977), these forming the first steps toward his current research. Fortunately, he also entered a joint project between Tokyo University, Osaka University, Kyoto University and Kobe University. That project helped Japan survive the first energy crisis and suggested many important decisions based on multiple viewpoints for industry development (economics), energy saving, environment protection and society needs. This formative experience triggered his interest in studying various fields and helped inspire his work in MCDM. Within all of these disciplines, Prof. Tzeng gained very high visibility because of his deep and thorough 
knowledge on a diverse range of topics. He also established theoretical backgrounds in soft computing, evolutionary computing and logic reasoning for his future MCDM research. At the same time, fuzzy set theory was flourishing in Japan. Under the direction of several internationally acknowledged professors (Hideo Tanaka, Masatoshi Sakawa, Masaharu Mizumoto, etc.), Tzeng published numerous journal papers in economics, urban planning, hospital management and many cross-field papers.

In 1977, Prof. Tzeng received his $\mathrm{PhD}$ degree in management science from Osaka University, Japan. He then returned to Tatung University in Taiwan as an Associate Professor for one year; then, he taught at National Chiao Tung University, Taiwan, from 1978 to 1981. Subsequently, Prof. Tzeng was a research associate at Argonne National Laboratory from 1981 to 1982, a visiting professor in the Department of Civil Engineering and Business School at the University of Maryland, College Park, from July 1989 to August 1990, and a visiting professor in the Department of Engineering and Economic System, Energy Modeling Forum at Stanford University from July 1997 to September 1998. These international experiences widened his global perspective.

During the time that Prof. Tzeng was at Argonne National Laboratory, the second worldwide energy crisis took place. He joined the energy and pollution effort and studied energy issues in transportation, family, business and industries. Upon returning from the United States, he created a Society of Energy Economics in Taiwan and joined a Chapter of IAEE (International Association for Energy Economics). He further helped Taiwan become a member of the World Energy Congress. He also learned "Habitual Domain" and "Competence Set Expansion" from Carl A. Scupin Distinguished Professor Po Lung Yu beginning in 1985. Later, in 1992, he and Professor Yu built a Society of Habitual Domain in Taiwan where he was the President for over 10 years. He advanced to a full professor at National Chaio Tung University during 1981 to 2003 and assumed the position of Chair Professor at National Chiao Tung University. He received the title of National Distinguished Chair Professor (the highest honor offered by the Ministry of Education Affairs, Taiwan) and Distinguished Research Fellow (Highest Honor Offered by NSC, Taiwan) in 2000. During his more than 30 years as a professor, he devoted his energy to areas of research, industry, government service and education. Prof. Tzeng consistently played a vital role in MCDM for management sciences, applying it to economics and business in Taiwan.

In addition to his enormous achievements in energy and transport policies of Taiwan and his wide and varied research activities, Prof. Tzeng was always a dedicated and enthusiastic participant in the education of students and researchers. His enthusiasm and magnetism were apparent to students when his lectures on research methods often continued until after 5 or even 6 oclock, extending beyond the scheduled ending of the class by more than one or two hours. He has mentored (either directly or indirectly) over 100 doctoral dissertations, and over 200 of his graduate students completed their MS thesis studies. Some of his former graduate students and former postdoctoral scholars are now actively working in as high-ranking officers in government, entrepreneurs in industry and scholars in academia. In the teaching and training of young researchers, he always emphasized the importance of integrated knowledge and aspiration levels. His motto is: "Avoid picking the best apple among a barrel of rotten apples and pursue a high aspiration level rather than just a relatively good one." Prof. Tzeng appeared to be a superman in his diligence when trying to resolve a problem. Almost every student has received a call from him at midnight when he was so excited by finding a solution that he wanted to share the results. He has written many books, such as 
Introduction to Modern Transportation Theory and Applications, Statistics, and Multivariate Theory and Applications (three volumes and the first Chinese book regarding multivariate analysis). Recently, he completed two books in English: Multi Attributes Decision Making and Fuzzy Multiple Objective Decision Making published by Taylor \& Francis (see Annex).

In addition to his extensive teaching accomplishments, Prof. Tzeng has received numerous distinguished achievements for his research. His research interests are wide-ranging and include statistics, multivariate analysis, network, routing and scheduling, multiple criteria decision making, fuzzy theory, hierarchical structure analysis for applying to technology management, energy, environment, transportation systems, transportation investment, logistics, location, urban planning, tourism, technology management, electronic commerce, and global supply chains. His paper "Compromise solution by MCDM methods: a comparative analysis of VIKOR and TOPSIS", as published in the "European Journal of Operational Research" on July $16^{\text {th }}, 156(2): 445-455,2004$, was noted as being a Highly Cited Paper on March $13^{\text {th }}$ by ESI and has been recently identified by Thomson Reuters' Essential Science Indicators ${ }^{S M}$ to be one of the most cited papers in the field of Economics. His papers were cited over 2000 times in 2012 according to Google Scholar ${ }^{1}$.

He received the MCDM Edgeworth-Pareto Award from the International Society on Multiple Criteria Decision Making (June, 2009), the Pinnacle of Achievement Award 2005 of the world, and the National Distinguished Chair Professor, the Award (the highest honor offered) of the Ministry of Education Affairs of Taiwan, three times the award of distinguished research and two times the award of distinguished research fellow (highest honor offered) of National Science Council of Taiwan. The $10^{\text {th }}$ MCDM Conference was organized by G. H. Tzeng and P. L. Yu in Taipei at the Asiaworld Plaza Hotel in July 19-24, 1992. The theme of the conference was "Expand and Enrich the Domains of Thinking and Applications". This conference is highly publicized in Taiwan. The conference attracted more than 300 people from 34 countries. He raised a large amount of money from sponsors and was able to host one of the grandest conferences, with a wonderful social program. The awards tradition started at this conference. The Gold Medal was awarded to Stanley Zionts, the EdgeworthPareto Award jointly to Po-Lung Yu and Milan Zelney, and the George Cantor Award was awarded to Andrzej Wierzbicki, all of whom were pioneers of MCDM. He has been a member of society of MCDM committee for many years. He came to know many foreign scholars in the MCDM field (e.g. Po-Lung Yu, M. Zeleny, David Bell, Valerie Belton, Harold Philip Benson, Denis Bouyssou, Jared L. Cohon, William Wager Cooper, Kalyanmoy Deb, James Dyer, Ward Edwards, Peter Fishburn, Tomas Gal, Arthur Geoffrion, Yacov Haimes, Raimo P. Hamalainen, Ralph L. Keeney, Murat Koksalan, Pekka Korhonen, Oleg Larichev, Alexander Lotov, Roman Slowinski, Benedeto Matarazzo, Salvatore Greco, Jaap Spronk, Ralph Steuer, Yong Shi, Masatoshi Sakawa, Thomas Saaty, Bernard Roy, Carlos Romero, Howard Raiffa, Hirotaka Nakayama, Kaisa Miettinen, Theodor J. Stewart, Philippe Vincke, Jyrki Wallenius, Andrzej Piotr Wierzbicki, and many other excellent scholars). In addition, he organized a Taiwan affiliate chapter of the International Association of Energy Economics in 1984; became Co-Chairman of the $36^{\text {th }}$ International Conference on Computers and Industrial Engineering in June 20-23, 2006, Taipei, Taiwan; and was Chairman of the International

http://scholar.google.com/citations?user=ZRXOrvQAAAAJ\&hl=en 
Summer School on Multiple Criteria Decision Making 2006 in July 2-14, Kainan University, Taiwan. He is a member of IAEE, ISMCDM, World Transport, the Operations Research Society of Japan, the Society of Instrument and Control Engineers Society of Japan, the City Planning Institute of Japan, the Behaviormetric Society of Japan, the Japan Society for Fuzzy Theory and Systems; and participates in numerous societies in Taiwan. He is also Editor-in-Chief of the International Journal of Information Systems for Logistics and Management. With the continuing input of his graduate students, post-doctoral fellows and research associates, as well as active collaborations with industrial and university researchers, it is expected that Prof. Tzeng's contributions will continue to be both numerous and of major significance to the field. With this paper, we join in wishing him the very best on the occasion of his $70^{\text {th }}$ birthday, and we also wish him continued health and productivity in the years ahead.

\section{Publication list}

Chen, C. H.; Tzeng, G. H. 2011. Creating the aspired intelligent assessment systems for teaching materials, Expert Systems with Applications 38(10): 12168-12179. http://dx.doi.org/10.1016/j.eswa.2011.03.050

Chen, F. H.; Hsu, T. S.; Tzeng, G. H. 2011. A balanced scorecard approach to establish a performance evaluation and relationship model for hot spring hotels based on a hybrid MCDM model combining DEMATEL and ANP, International Journal of Hospitality Management 30(4): 908-932. http://dx.doi.org/10.1016/j.ijhm.2011.02.001

Chen, M. F.; Tzeng, G. H. 2004. Combining grey relation and TOPSIS concepts for selecting an expatriate Host Country, Mathematical and Computer Modelling 40(13): 1473-1490.

http://dx.doi.org/10.1016/j.mcm.2005.01.006

Chen, M. F.; Tzeng, G. H.; Ding, C. G. 2008. Combing fuzzy AHP with MDS in identifying the preference similarity of alternatives, Applied Soft Computing 8(1): 110-117. http://dx.doi.org/10.1016/j.asoc.2006.11.007

Chen, V. Y. C.; Lien, H. P.; Liu, C. H.; Liou, J. J. H.; Tzeng, G. H.; Yang, L. S. 2011. Fuzzy MCDM approach for selecting the best environment-watershed plan, Applied Soft Computing 11(1): 265-275. http://dx.doi.org/10.1016/j.asoc.2009.11.017

Chen, T. Y.; Chang, H. L.; Tzeng, G. H. 2002. Using fuzzy measure and habitual domains to analyze the public attitude and apply to the gas taxi policy, European Journal of Operational Research 137(2): 145-161. http://dx.doi.org/10.1016/S0377-2217(01)00137-0

Chen, T. Y.; Wang, J. C.; Tzeng, G. H. 2000. Identification of general fuzzy measures by genetic algorithms based on partial information, IEEE Transactions on Systems, Man, and Cybernetics Part B: Cybernetics 30B(4): 517-528. http://dx.doi.org/10.1109/3477.865169

Chen, Y. C.; Lien, H. P.; Tzeng, G. H. 2010. Measures and evaluation for environment watershed plan using a novel hybrid MCDM model, Expert Systems with Applications 37(2): 926-938. http://dx.doi.org/10.1016/j.eswa.2009.04.068

Chen, Y. W.; Tzeng, G. H. 2001. Using fuzzy integral for evaluating subjectively perceived travel costs in a traffic assignment model, European Journal of Operational Research 130(3): 653-664. http://dx.doi.org/10.1016/S0377-2217(99)00439-7

Cheng, J. W.; Chiu, W. L.; Tzeng, G. H. 2013. Do impression management tactics and/or supervisor-subordinate guanxi matter?, Knowledge-Based Systems 40: 123-133. http://dx.doi.org/10.1016/j.knosys.2012.12.002

Chiou, H. K.; Tzeng, G. H. 2002. Fuzzy multiple-criteria decision-making approach for industrial green engineering, Environmental Management 30(6): 816-830. http://dx.doi.org/10.1007/s00267-002-2673-Z

Chiu, W. Y.; Tzeng, G. H.; Li, H. L. 2013. A new hybrid MCDM model combining DANP with VIKOR to improve e-store business, Knowledge-Based Systems 37(1): 48-61.

http://dx.doi.org/10.1016/j.knosys.2012.06.017 
Chu, M. T.; Shyu, J. Z.; Tzeng, G. H. 2007. Using non-additive fuzzy integral to assess performances of organization transformation via communities of practice, IEEE Transactions on Engineering Management 54(2): 327-339. http://dx.doi.org/10.1109/TEM.2007.893987

Fang, S. K.; Shyng, J. Y.; Lee, W. S.; Tzeng, G. H. 2012. Combined data mining techniques for exploring the preference of customers between financial companies and agents based on TCA, Knowledge-Based Systems 27: 137-151. http://dx.doi.org/10.1016/j.knosys.2011.09.003

Ho, J. W. R.; Tsai, C. L.; Tzeng, G. H.; Fang, S. K. 2011. Combined DEMATEL technique with a novel MCDM model for exploring portfolio selection based on CAPM, Expert Systems with Applications 38(1): 16-25. http://dx.doi.org/10.1016/j.eswa.2010.05.058

Hsieh, T. Y.; Lu, S. T.; Tzeng, G. H. 2004. Fuzzy MCDM approach for planning and design tenders selection in public office buildings, International Journal of Project Management 22(7): 573-584. http://dx.doi.org/10.1016/j.ijproman.2004.01.002

Hsu, C. H.; Wang, F. K.; Tzeng, G. H. 2012. The best vendor selection for conducting the recycled material based on a hybrid MCDM model combining DANP with VIKOR, Resources, Conservation \& Recycling 66: 95-111. http://dx.doi.org/10.1016/j.resconrec.2012.02.009

Hu, S. K.; Chuang, Y. C.; Yeh, Y. F.; Tzeng, G. H. 2012. Combining hybrid MADM with fuzzy integral for exploring the smart phone improvement in M-Generation, International Journal of Fuzzy Systems 14(2): 204-214.

Huang, J. J.; Tzeng, G. H. 2013. New thinking of multi-objective programming with changeable space - in search of excellence, Technological and Economic Development of Economy (in Press).

Hung, Y. H.; Chou, T. S. C.; Tzeng, G. H. 2011. Knowledge management adoption and assessment for SMEs by a novel MCDM approach, Decision Support Systems 51(2): 270-291.

http://dx.doi.org/10.1016/j.dss.2010.11.021

Jeng, D. J. F.; Tzeng, G. H. 2012. Social influence on the use of clinical decision support systems: revisiting the unified theory of acceptance and use of technology by the fuzzy DEMATEL technique, Computers \& Industrial Engineering 62(3): 819-828. http://dx.doi.org/10.1016/j.cie.2011.12.016

Ko, Y. C.; Fujita, H.; Tzeng, G. H. 2013. A fuzzy integral fusion approach in analyzing competitiveness patterns from WCY2010, Knowledge-Based Systems in Press, Available online 9 May 2013. http://dx.doi.org/10.1016/j.knosys.2013.04.001

Ko, Y. C.; Fujita, H.; Tzeng, G. H. 2013. An extended fuzzy measure on competitiveness correlation based on WCY 2011, Knowledge-Based Systems 37(1): 86-93. http://dx.doi.org/10.1016/j.knosys.2012.07.010

Kuan, M. J.; Tzeng, G. H.; Hsiang, C. C. 2012. Probing the innovative quality system structure model for NPD process based on combining DANP with MCDM model, International Journal of Innovative Computing, Information and Control 8(8): 5745-5762.

Kuo, M. S.; Tzeng, G. H.; Huang, W. C. 2007. Group decision making based on concepts of ideal and anti-ideal points in fuzzy environment, Mathematical and Computer Modeling 45(3-4): 324-339. http://dx.doi.org/10.1016/j.mcm.2006.05.006

Larbani, M.; Huang, C. Y.; Tzeng, G. H. 2011. A novel method for fuzzy measure identification, International Journal of Fuzzy Systems 13(1): 24-34.

Lee, H. S.; Tzeng, G. H.; Yeih, W.; Wang, Y. J.; Yang, S. C. 2013. Revised DEMATEL: resolving the infeasibility of DEMATEL, Applied Mathematical Modelling 37(10-11): 6746-6757. http://dx.doi.org/10.1016/j.apm.2013.01.016

Liou, J. J. H.; Tzeng, G. H. 2010. Dominance-based rough set approach for customer behavior in the airline market, Information Sciences 180(11): 2230-2238. http://dx.doi.org/10.1016/j.ins.2010.01.025

Liou, J. J. H.; Tzeng, G. H. 2011. A hybrid ANP model in fuzzy environments for strategic alliance partner selection in the airline industry, Applied Soft Computing 11(4): 3515-3524.

http://dx.doi.org/10.1016/j.asoc.2011.01.024 
Liou, J. J. H.; Tzeng, G. H. 2012. Comments on "Multiple criteria decision making (MCDM) methods in economics: An overview", Technological and Economic Development of Economy 18(4): 672-695. http://dx.doi.org/10.3846/20294913.2012.753489

Liou, J. J. H.; Yen, L.; Tzeng, G. H. 2010. Using decision rules to help airlines cut costs without sacrificing essential service quality, European Journal of Operational Research 205(3): 680-686. http://dx.doi.org/10.1016/j.ejor.2009.11.019

Liu, C. H.; Tzeng, G. H.; Lee, M. H. 2012. Improving tourism policy implementation - the use of hybrid MCDM models, Tourism Management 33(2): 239-488. http://dx.doi.org/10.1016/j.tourman.2011.05.002

Opricovic, S.; Tzeng, G. H. 2003. Defuzzification within a fuzzy multicriteria decision model, International Journal of Uncertainty, Fuzziness and Knowledge-Based Systems 11(5): 635-652. http://dx.doi.org/10.1142/S0218488503002387

Opricovic, S.; Tzeng, G. H. 2004. Compromise solution by MCDM methods: a comparative analysis of VIKOR and TOPSIS, European Journal of Operational Research 156(2): 445-455. http://dx.doi.org/10.1016/S0377-2217(03)00020-1

Opricovic, S.; Tzeng, G. H. 2007. Extended VIKOR method in comparison with outranking methods, European Journal of Operational Research 178(2): 514-529. http://dx.doi.org/10.1016/j.ejor.2006.01.020

Ou Yang, Y. P.; Shieh, H. M.; Tzeng, G. H. 2012. A VIKOR technique based on DEMATEL and ANP for information security risk control assessment, Information Sciences 232: 482-500. http://dx.doi.org/10.1016/j.ins.2011.09.012

Ou Yang, Y. P.; Shieh, H. M.; Tzeng, G. H., Yen, L.; Chan, C. C. 2011. Combined rough sets with flow graph and formal concept analysis for business aviation decision-making, Journal of Intelligent Information Systems 36(3): 347-366. http://dx.doi.org/10.1007/s10844-009-0110-y

Peng, K. H.; Tzeng, G. H. 2013. A hybrid dynamic MADM model for problems-improvement in economics and business, Technological and Economic Development of Economy, (in Press).

Shyng, J. J.; Shieh, H. M.; Tzeng, G. H.; Hsieh, S. H. 2010. Using FSBT technique with rough set theory for personal investment portfolio analysis, European Journal of Operational Research 201(2): 601-607. http://dx.doi.org/10.1016/j.ejor.2009.03.031

Shyng, J. Y.; Shieh, H, M.; Tzeng, G. H. 2011. An integration method combined rough set theory with formal concept analysis for personal investment portfolios, Knowledge-Based Systems 23(6): 586-597. http://dx.doi.org/10.1016/j.knosys.2010.04.003

Shyng, J. Y.; Shieh, H. M.; Tzeng, G. H. 2011. Compactness rate as a rule selection index based on rough set theory to improve data analysis for personal investment portfolios, Applied Soft Computing 11(4): 3671-3679. http://dx.doi.org/10.1016/j.asoc.2011.01.038

Tsai, H. C.; Chen, C. M.; Tzeng, G. H. 2006. The comparative productivity efficiency for global telecoms, International Journal of Production Economics 103(2): 509-526. http://dx.doi.org/10.1016/j.

Tzeng, G. H.; Chen, W. H.; Yu, R.; Shih, M. L. 2010. Fuzzy decision maps- a generalization of the DEMATEL methods, Soft Computing 14(11): 1141-1150. http://dx.doi.org/10.1007/s00500-009-0507-0

Tzeng, G. H.; Chiang, C. H.; Li, C. W. 2007. Evaluating intertwined effects in e-learning programs: a novel hybrid MCDM model based on factor analysis and DEMATEL, Expert Systems with Applications 32(4): 1028-1044. http://dx.doi.org/10.1016/j.eswa.2006.02.004

Tzeng, G. H.; Huang, C. Y. 2012. Combined DEMATEL technique with hybrid MCDM methods for creating the aspired intelligent global manufacturing \& logistics systems, Annals of Operations Research 19(1): 159-190. http://dx.doi.org/10.1007/s10479-010-0829-4

Tzeng, G. H.; Lin, C. W.; Opricovic, S. 2005. Multi-criteria analysis of alternative-fuel buses for public transportation, Energy Policy 33(1): 1373-1383. http://dx.doi.org/10.1016/j.enpol.2003.12.014

Tzeng, G. H.; Ou Yang, Y. P.; Lin, C. T.; Chen, C. B. 2005. Hierarchical MADM with fuzzy integral for evaluating enterprise intranet web sites, Information Sciences 169(3-4): 409-426.

http://dx.doi.org/10.1016/j.ins.2004.07.001 
Tzeng, G. H.; Teng, M. H.; Chen, J. J.; Opricovic, S. 2002. Multicriteria selection for a restaurant location in Taipei, International Journal of Hospitality Management 21(2): 171-187. http://dx.doi.org/10.1016/S0278-4319(02)00005-1

Tzeng, G. H.; Tsaur, S. H.; Laiw, Y. D.; Opricovic, S. 2002. Multicriteria analysis of environmental quality in Taipei: public preferences and improvement strategies, Journal of Environmental Management 65(2): 109-120. http://dx.doi.org/10.1006/jema.2001.0527

Wang, C. H.; Chin, Y. C.; Tzeng, G. H. 2010. Mining the R\&D innovation performance processes for high-tech firms based on rough set theory, Technovation 30(7-8): 447-458. http://dx.doi.org/10.1016/j.technovation.2009.11.001

Wang, Y. L.; Tzeng, G. H. 2012. Brand marketing for creating brand value based on a MCDM model combining DEMATEL with ANP and VIKOR methods, Expert Systems with Applications 39(5): 5600-5615. http://dx.doi.org/10.1016/j.eswa.2011.11.057

Wei, P. L.; Huang, J. H.; Tzeng, G. H.; Wu, S. I. 2010. Causal modeling of web-advertising effects by improving effects by improving SEM based on DEMATEL technique, International Journal of Information Technology \& Decision Making 9(5): 799-829. http://dx.doi.org/10.1142/S0219622010004032

Wu, C. H.; Tzeng, G. H.; Goo, Y. J.; Fang, W. C. 2007. A real-valued genetic algorithm to optimize the parameters of support vector machine for predicting bankruptcy, Expert Systems with Applications 32(2): 397-408. http://dx.doi.org/10.1016/j.eswa.2005.12.008

James J. H. LIOU received his PhD degree from the Department of Mechanical and Aerospace Engineering of University of Missouri-Columbia, USA in 1996. After working in airline industry for 8 years, he became an assistant professor at the Department of Air Transportation, Kainan University, Taiwan. $\mathrm{He}$ has become an associate professor in 2008. Currently, he is an associate professor at the Department of Industrial Engineering and Management at National Taipei University of Technology. He has publications in numerous journals, including Journal of Air Transport Management, Expert Systems with Applications, International Journal of Production Research, Applied Soft computing, Information Sciences and European Journal of Operational Research, etc. Dr Liou's primary research interest is data mining, including feature selection, clustering, ensemble methods, and decision support systems. Recently, he became interested in applying data mining algorithms to solve some business problems in customer targeting, e-commerce, and safety science. 